\section{Commentary: The shortfall of annular repair for functional tricuspid regurgitation}

\author{
Leora B. Balsam, MD
}

The survival disadvantage of uncorrected functional tricuspid regurgitation (TR) has led to more aggressive surgical treatment of TR at the time of left-sided valvular surgery. No longer a forgotten valve, current American College of Cardiology/American Heart Association guidelines recommend concomitant correction of TR based on regurgitation grade, annular dimension, and signs of right heart failure. ${ }^{1}$ Most repair techniques for functional TR focus on annular remodeling, which is often sufficient to achieve a good result. In their series of 790 patients undergoing tricuspid annuloplasty with 4 different techniques, McCarthy and colleagues ${ }^{2}$ in Cleveland reported a $15 \%$ prevalence of $3-4+$ TR within 1 month of surgery. This high rate of early technical failure was similar across repair techniques, which included semirigid ring, flexible band, De Vega suture annuloplasty, and bovine pericardial annuloplasty. Over time, the prevalence of 3-4+ TR remained stable in the semi-rigid annuloplasty group; however, it rose rapidly in the suture annuloplasty and bovine pericardial annuloplasty group. A later study by Filsoufi and colleagues ${ }^{3}$ found that better early outcomes could be achieved using a semi-rigid remodeling ring and more aggressive annular down-sizing.

In this issue of the Journal, Amedi and colleagues ${ }^{4}$ take us back from the bedside to the bench and put several repair techniques for functional TR to the test. By increasing right ventricular afterload, functional $\mathrm{TR}$ is generated in an ex vivo model consisting of a porcine heart connected to a pulsatile flow loop. Two repair techniques are compared; remodeling annuloplasty with the Edwards MC3 ring and focal

From the Division of Cardiac Surgery, UMass Memorial Medical Center, Worcester, Mass.

Disclosures: The author reported no conflicts of interest.

The Journal policy requires editors and reviewers to disclose conflicts of interest and to decline handling or reviewing manuscripts for which they may have a conflict of interest. The editors and reviewers of this article have no conflicts of interest.

Received for publication Sept 2, 2020; revisions received Sept 2, 2020; accepted for publication Sept 3, 2020; available ahead of print Sept 10, 2020.

Address for reprints: Leora B. Balsam, MD, Division of Cardiac Surgery, UMass Memorial Medical Center, University Campus, 55 Lake Ave North, Worcester, MA 01655 (E-mail: leora.balsam@umassmemorial.org).

J Thorac Cardiovasc Surg 2022; $164: 88-9$

$0022-5223 / \$ 36.00$

Copyright (C) 2020 by The American Association for Thoracic Surgery

https://doi.org/10.1016/j.jtcvs.2020.09.022

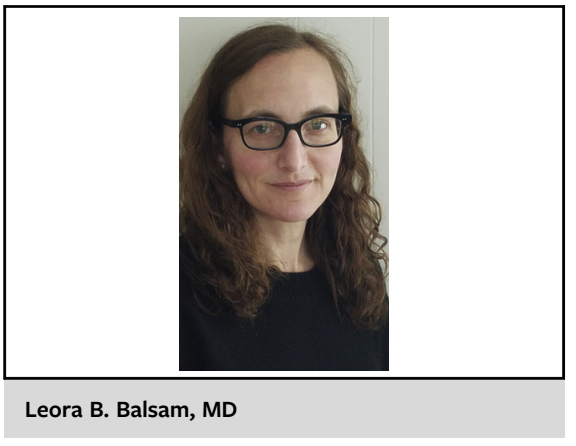

CENTRAL MESSAGE

A new study examines the basis

of functional tricuspid regurgita-

tion and evaluates 2 annular-

based repairs using an ex vivo

simulator.

suture annuloplasty (a technique that creates a double orifice valve by approximating the midpoint of the anterior annulus with the contralateral septal annulus ${ }^{5}$ ). Using the simulator, they measure changes in regurgitant fraction, annular dimension, tenting area, coaptation length, and leaflet excursion area. Interestingly, they find that neither technique is enough to eliminate the functional TR induced by pressure overload, likely due to leaflet tethering. This experimental finding validates what had been shown clinically by the Cleveland Clinic group: leaflet tethering is an important predictor of residual TR after tricuspid valve annuloplasty. ${ }^{6}$

The authors' experimental findings lend support to the premise that an annular solution may not be enough to correct the geometric deformities that result in functional TR. They suggest that subvalvular repairs may also be needed. De Bonis and colleagues ${ }^{7}$ have taken a different approach, extending their edge-to-edge approach to the tricuspid valve with the "clover technique," creating a triple orifice tricuspid valve. Their clinical experience using the "clover technique" as an adjunct to annuloplasty for complex TR has been good, with only $1.2 \%$ incidence of $3-4+\mathrm{TR}$ at 12 -years' follow-up in a series of 96 patients.

In Amedi and colleagues' model, ${ }^{4}$ the degree of failure of the repair techniques (particularly the well-established semirigid remodeling technique) seems greater than expected based on published clinical experience. It is unclear whether this relates to specific limitations of the simulator, the degree of annular remodeling, or challenges in correlating in vivo measurements to experimental ones ex vivo. Regardless, the 
model may be a useful tool for developing novel adjunctive repair techniques that focus on the subvalvular apparatus.

\section{References}

1. Nishimura RA, Otto CM, Bonow RO, Carabello BA, Erwin EP, Guyton RA, et al. 2014 AHA/ACC guideline for the management of patients with valvular heart disease: executive summary. Circulation. 2014;129:2440-92.

2. McCarthy PM, Bhudia SK, Rajeswaran J, Hoercher KJ, Lytle BW, Cosgrove DM, et al. Tricuspid valve repair: durability and risk factors for failure. J Thorac Cardiovasc Surg. 2004;127:674-85.

3. Filsoufi F, Salzberg SP, Coutu M, Adams DH. A three-dimensional ring annuloplasty for the treatment of tricuspid regurgitation. Ann Thorac Surg. 2006;81:2273-8.
4. Amedi A, Ohohara D, Xu D, Suresh KS, Padala M. Hemodynamic outcomes after undersizing ring annuloplasty and focal suture annuloplasty for surgical repair of functional tricuspid regurgitation. J Thorac Cardiovasc Surg. 2022; 164:76-87.e1.

5. Hetzer R. The double orifice valve technique to treat tricuspid valve incompetence. J Cardiothorac Surg. 2013;8(suppl 1):O103.

6. Fukuda S, Song JM, Gillinov AM, McCarthy PM, Daimon M, Kongsaerepong V et al. Tricuspid valve tethering predicts residual tricuspid regurgitation after tricuspid annuloplasty. Circulation. 2005;111:975-9.

7. De Bonis M, Lapenna E, Di Sanzo S, Del Forno B, Pappalardo F, Castiglioni A, et al. Long-term results (up to 14 years of the clover technique for the treatment of complex tricuspid valve regurgitation. Eur J Cardiothorac Surg. 2017;52: 125-30.
See Article page 76.

\section{Commentary: Tricuspid regurgitation: When a repair is not just a repair}

\author{
Peter J. Altshuler, MD, and Pavan Atluri, MD
}

The management of functional tricuspid regurgitation (FTR) is evolving as we add to our understanding of the disease. With the prevalence of moderate-to-severe FTR approaching 3 million people in the United States, ${ }^{1,2}$ improvements in treatment have the potential to affect morbidity and mortality on a large scale. Current practice is dictated largely by valve repair intended to restore valve competence through a spectrum of annuloplasty techniques; unfortunately, while largely successful in improving valve geometry and mechanics, residual TR is common. ${ }^{3}$

In this issue of the Journal, Amedi and colleagues set out to help answer the question of how to better surgically repair severe FTR. ${ }^{6}$ Using an ex vivo porcine model of isolated TR, the authors were able to provide a unique and detailed insight into the structure and function of the tricuspid valve and right ventricle (RV) after either ring or

\footnotetext{
From the Division of Cardiovascular Surgery, Department of Surgery, University of Pennsylvania, Philadelphia, Pa.

Disclosures: The authors reported no conflicts of interest.

The Journal policy requires editors and reviewers to disclose conflicts of interest and to decline handling or reviewing manuscripts for which they may have a conflict of interest. The editors and reviewers of this article have no conflicts of interest.

Received for publication Sept 18, 2020; revisions received Sept 18, 2020; accepted for publication Sept 22, 2020; available ahead of print Sept 30, 2020.

Address for reprints: Pavan Atluri, MD, Division of Cardiovascular Surgery, Department of Surgery, Hospital of the University of Pennsylvania, 3400 Spruce St, 6 Silverstein, Philadelphia, PA 19104 (E-mail: pavan.atluri@pennmedicine.upenn. edu).

J Thorac Cardiovasc Surg 2022;164:89-90

$0022-5223 / \$ 36.00$

Copyright (c) 2020 by The American Association for Thoracic Surgery

https://doi.org/10.1016/j.jtcvs.2020.09.083
}

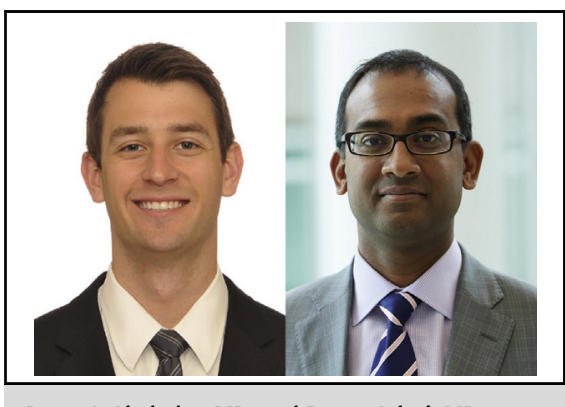

Peter J. Altshuler, MD, and Pavan Atluri, MD

CENTRAL MESSAGE

Better understanding of

tricuspid valve and right ventric-

ular mechanics after tricuspid

valve repair provide clarity into

optimal surgical management.

focal-cinching Hetzer suture annuloplasty. Overall, while both techniques were able to reduce FTR, neither was able to completely restore valve competence. Through detailed echocardiographic assessment of the valve apparatus and $\mathrm{RV}$, residual regurgitation was found to be a result of ongoing RV wall displacement. Without addressing this displacement, papillary muscles inserting on the RV free wall caused persistent valve tethering. This finding provides further insight into an important shortcoming in current management of severe FTR: without addressing associated subvalvular pathology, residual TR is likely irrespective of repair technique.

The findings demonstrated in this study provide valuable insight into how current surgical therapy alters the already 